\title{
Do plot studies generate "directionally" correct assessments of field-level phosphorus losses?
}

\section{D.R. Smith and E. Pappas}

\begin{abstract}
The National Phosphorus Research Project coordinated a tremendous amount of research at the plot scale to assess the influence of nutrient management on phosphorus $(\mathrm{P})$ transport at the fields scale. The objective of this research was to determine if plot-scale rainfall simulations could be used to assess $\mathrm{P}$ transport from two fields that were managed using notillage or rotational tillage. Plots were constructed within the management zone but adjacent to monitored fields. Phosphorus transport at the field scale from throughout the growing season was compared to confidence limits established by the rainfall simulations, and a secondary analysis compared values from individual storms to the rainfall simulations. Soluble phosphorus (SP) loads from the no-tillage AS1 field $\left(75 \mathrm{~g} \mathrm{ha}^{-1}\left[0.066 \mathrm{lb} \mathrm{ac}^{-1}\right]\right)$ were greater than from the rotationally tilled AS2 field $\left(11 \mathrm{~g} \mathrm{ha}^{-1}\left[0.010 \mathrm{lb} \mathrm{ac}^{-1}\right]\right)$ in 2004. Stratification of $\mathrm{P}$ in the uppermost portion of the soil profile is a known contributor to SP loading in long-term no-tillage fields. This trend was reversed in 2006 though, as SP loads were $16 \mathrm{~g}$ $\mathrm{ha}^{-1}\left(0.014 \mathrm{lb} \mathrm{ac}^{-1}\right)$ from the AS1 field and $55 \mathrm{~g} \mathrm{ha}^{-1}\left(0.049 \mathrm{lb} \mathrm{ac}^{-1}\right)$ from the AS2 field. The greater loads from the AS2 field were due to greater discharge and a greater $\mathrm{P}$ application rate, compared to the AS1 field. Soluble P and total P loads were generally directionally correct, but the values obtained from plots were not necessarily similar to those observed at the field scale. Precipitation normalized loads for SP and total P were the most similar metric when comparing values from the plot to the field scale (i.e., more field scale values fell within the $95 \%$ confidence limits set by the plot data than the other metrics). Using cumulative fieldscale data from each year or the mean values from storms by year did not appear to change the results of this study. This study would appear to confirm that the management decisions based on the National Phosphorus Research Project are likely to be sound and will probably lead to improved quality of runoff water from fields. Precipitation normalized loads appear to be a metric that may provide additional insight into $\mathrm{P}$ transport at various scales.
\end{abstract}

Key words: Conservation Effects Assessment Project—no-tillage-rotational tillage-water quality

\begin{abstract}
Agricultural nonpoint sources of phosphorus $(P)$ have been identified as one of the primary contributors to eutrophication in fresh water reservoirs and lakes and are also linked to the degradation of water quality in the Chesapeake Bay and the Gulf of Mexico (Carpenter et al. 1998; Sundareshwar et al. 2003).
\end{abstract}

Recently, efforts have been undertaken in the United States to develop P indices to assess the risk of manure and fertilizer management practices on water quality. Much of this work has been done using a standardized rainfall simulation methodology, known as the National Phosphorus Research Project (NPRP), developed by experts in the field (SERA-17, 2008). As a part of the NPRP, many rainfall simulations were conducted on plots with a slope length of $2 \mathrm{~m}$ (6.6 ft). A question has often been raised as to the applicability of measuring nutrient concentrations or loads at the plot scale (i.e., 1.5 to $2 \mathrm{~m}^{2}$ [16 to $\left.22 \mathrm{ft}^{2}\right]$ ) when the overarching goal was to evaluate the effect of nutrient management at the field scale (1 to 100 ha [2.5 to $250 \mathrm{ac}]$ ).
One could argue that data from the plot scale is not applicable to the field scale, as the processes of hydrology and nutrient transport at these scales are quite different. For example, Bloschl and Sivapalan (1995) describe hydrologic processes at various spatial and temporal scales. Since P transport is predominately driven by hydrology, a similar conceptual model of spatiotemporal scale could be proposed for $\mathrm{P}$ transport (figure 1). Many of the same hydrologic pathways in the Bloschl and Sivapalan (1995) model, such as saturation excess overland flow, infiltration excess overland flow, and channel flow, are quite applicable to $\mathrm{P}$ transport pathways. Additional consideration must be given to other aspects of $\mathrm{P}$ transport, such as the adsorption/desorption/precipitation reactions that occur at a molecular level with soil particles and other dissolved elements (Pote et al. 2003; Sharpley 2003; Suzuki et al. 2005). Research has also led to the knowledge that $\mathrm{P}$ is lost via subsurface flow pathways, including preferential flow pathways to subsurface drainage tiles (Gachter et al. 1998; Haygarth et al. 1998).

Using this approach, plot-scale work would be applicable from the minutes to hours temporal range, and 1 to $10 \mathrm{~m}(3.3$ to $33 \mathrm{ft}$ ) range spatially. Field-scale research would cover the temporal scale of days to

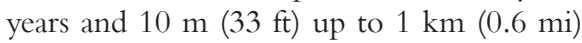
on the spatial scale. Observations made at the plot scale are the integration processes from lower time and space scales on our conceptual plot. For example, during a rainfall simulation on a soil that is unsaturated and lacks layers that would limit infiltration (i.e., a fragipan), the runoff is predominately generated as infiltration excess overland flow (Kleinman et al. 2006). Phosphorus transport observations made from rainfall simulation studies are a result of infiltration excess overland flow as well as the lower order spatiotemporal processes, including adsorption/desorption/precipitation reactions, micropore flow, and interflow. As one moves from the plot to the field scale, the overarching processes controlling $\mathrm{P}$ fate and transport include saturation excess flow

Douglas R. Smith is a research soil scientist, and Elizabeth Pappas is a research hydraulic engineer at the USDA Agricultural Research Service National Soil Erosion Research Laboratory in West Lafayette, Indiana. 
and potentially tile riser flow, subsurface tile flow, and groundwater flow.

The primary purpose of the NPRP was to assist researchers in developing risk factors for management practices relative to other management practices. Thus, one could argue that to compare data from NPRP plots to field- or watershed-scale data would be to make interpolations far beyond what the NPRP was intended to represent. There have been a few studies to examine the spatial scaling influences of box- and plot-scale simulation work using the NPRP protocols (Sharpley and Kleinman 2003; Kleinman et al. 2004; Guidry et al. 2006). Kleinman et al. (2004) and Guidry et al. (2006) compared the results of rainfall simulations on small boxes $\left(0.2 \mathrm{~m}^{2}\left[2 \mathrm{ft}^{2}\right]\right)$ in the laboratory to rainfall simulations to plots ( 2 and $4 \mathrm{~m}^{2}$ [22 and $43 \mathrm{ft}^{2}$, respectively) in the field environment. Sharpley and Kleinman (2003) compared results from the NPRP protocol $\left(2 \mathrm{~m}^{2}\left[22 \mathrm{ft}^{2}\right]\right.$ plots) to another protocol that used a larger plot size $\left(32.6 \mathrm{~m}^{2}\left[350 \mathrm{ft}^{2}\right]\right)$. These studies compared $\mathrm{P}$ loss parameters for soils from the same fields/catchments, whereas small-scale studies are often used to develop or calibrate models based on data from one field or catchment, which is then applied to another catchment. This concept is known as regionalization and can result in faulty assumptions when basic underlying properties, such as geology or watershed size/shape characteristics, are different for the two catchments (Bloschl and Sivapalan 1995; Sivapalan et al. 2003).

Much of the plot-scale research for the NPRP was conducted to assess what has been termed the "directionality" of treatments, i.e., to compare various treatments to determine which might have the greatest relative impact at the field scale for reducing $\mathrm{P}$ losses to surface water. The term "directionality" refers to the concept that plot-scale data information should be applicable to $\mathrm{P}$ transport behavior at the field scale in a relative sense but not in an absolute sense (i.e., prediction of actual load or concentration). This concept suggests that one should be able to adequately determine which treatment will work better at the field scale by using cheaper and quicker plot-scale work than the more labor-intensive, expensive, and less repeatable field-scale assessments. DeLaune et al. (2004a) developed a phosphorus index (PI) from plot-scale work (3 $\left.\mathrm{m}^{2}\left[32 \mathrm{ft}^{2}\right]\right)$ and applied that PI to two fields

\section{Figure 1}

Conceptual model for spatial and temporal scales governing phosphorus transport.

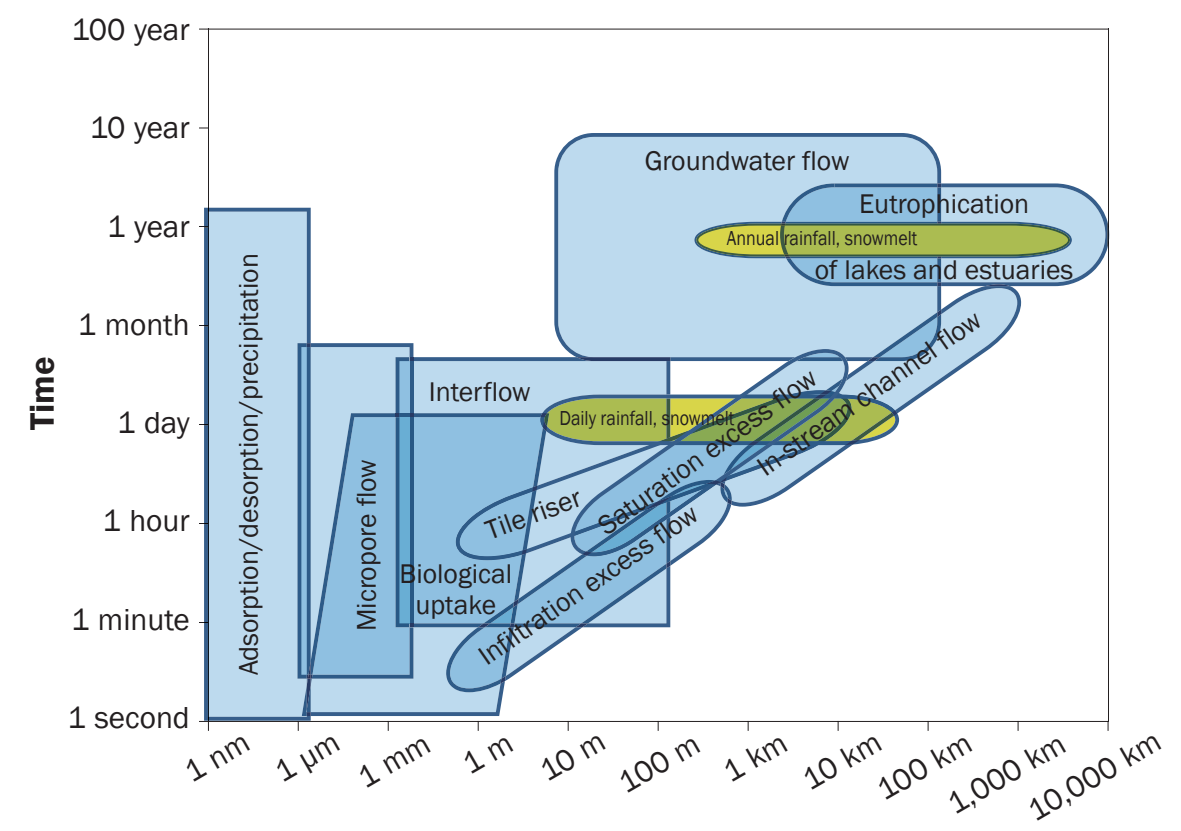

Distance

(0.405 ha $[1 \mathrm{ac}])$ that were approximately $40 \mathrm{~km}(25 \mathrm{mi})$ from the plots where the PI was developed (DeLaune et al. 2004b). They observed that greater PI rating values reasonably estimated $\left(r^{2}=0.83\right) \mathrm{P}$ losses at the field scale. While the PI was developed for their work using plot-scale information, the plots and the fields studied were in different watersheds and thus were not directly comparable. Thus there is still a need to evaluate how well plot-scale rainfall simulation data evaluate the influence of management on $\mathrm{P}$ runoff from fields.

The objective of the current research was to determine if plot-scale $\mathrm{P}$ loss data could be used to provide information on how management may affect $\mathrm{P}$ transport at the field scale (for both individual runoff events and the growing season). A secondary objective was added to determine if a measure of $\mathrm{P}$ loss normalized for precipitation could provide useful information about $\mathrm{P}$ losses at multiple scales. In order to accomplish these objectives, we used data from rainfall simulation studies conducted in 2004 and 2006 and from monitored fields that the plots were nested in for 2004 and 2006.

\section{Materials and Methods}

This research was conducted within the St. Joseph River watershed in northeast
Indiana, which is monitored by the USDA Agricultural Research Service for the cropland Conservation Effects Assessment Project (CEAP) (Smith et al. 2008). Plots were constructed in the AS1 (2.2 ha [5.4 ac]) and AS2 (2.7 ha $[6.7 \mathrm{ac}])$ fields, just outside of the area drained through the drop box weirs but inside the same management area of the monitored drainage area (figure 2). For each set of plots constructed in 2004, there was one plot measuring $2 \times 1 \mathrm{~m}(6.6 \times 3.3 \mathrm{ft})$, one plot measuring $5 \times 1 \mathrm{~m}(16 \times 3.3 \mathrm{ft})$, and another plot measuring $10 \times 1 \mathrm{~m}(33$ $\times 3.3 \mathrm{ft})$. Each group of three plots $(2,5$, and $10 \mathrm{~m}^{2}\left[22,54\right.$, and $\left.\left.108 \mathrm{ft}^{2}\right]\right)$ was considered to be one replicate, and there were three replicates in each field. The $1 \mathrm{~m}(3.3$ $\mathrm{ft}$ ) plot width was constant for all three flow path lengths so that a single rainfall simulation setup could rain on all three plots from one replication at once. The rainfall simulation equipment had a rainfall footprint of $12 \times 3 \mathrm{~m}(39 \times 10 \mathrm{ft})$ so an area of $10 \times 2.25$ $\mathrm{m}(33 \times 7.4 \mathrm{ft})$ was used in the center of this footprint for placing the plots. In 2006, the $5 \mathrm{~m}$ (16 ft) plots were replaced with a second $2 \mathrm{~m}(6.6 \mathrm{ft})$ plot that was used for a different set of objectives.

The rainfall simulators used oscillating Veejet 80100 nozzles spaced $1.1 \mathrm{~m}(3.6 \mathrm{ft}$ ) apart and $2.5 \mathrm{~m}(8.2 \mathrm{ft})$ above the soil surface. 


\section{Figure 2}

Map showing the sites used for this study, including the plots (adjacent to AS1 and AS2 fields) and the fields ( $A S_{1}$ and $A_{2}$ ). The plots were in the fields of $A_{1} 1$ and $A_{2}$ but outside of the area draining into the drop box weir. The fields are within the Cedar Creek subwatershed, which is a part of the of the St. Joseph River watershed in northeast Indiana.

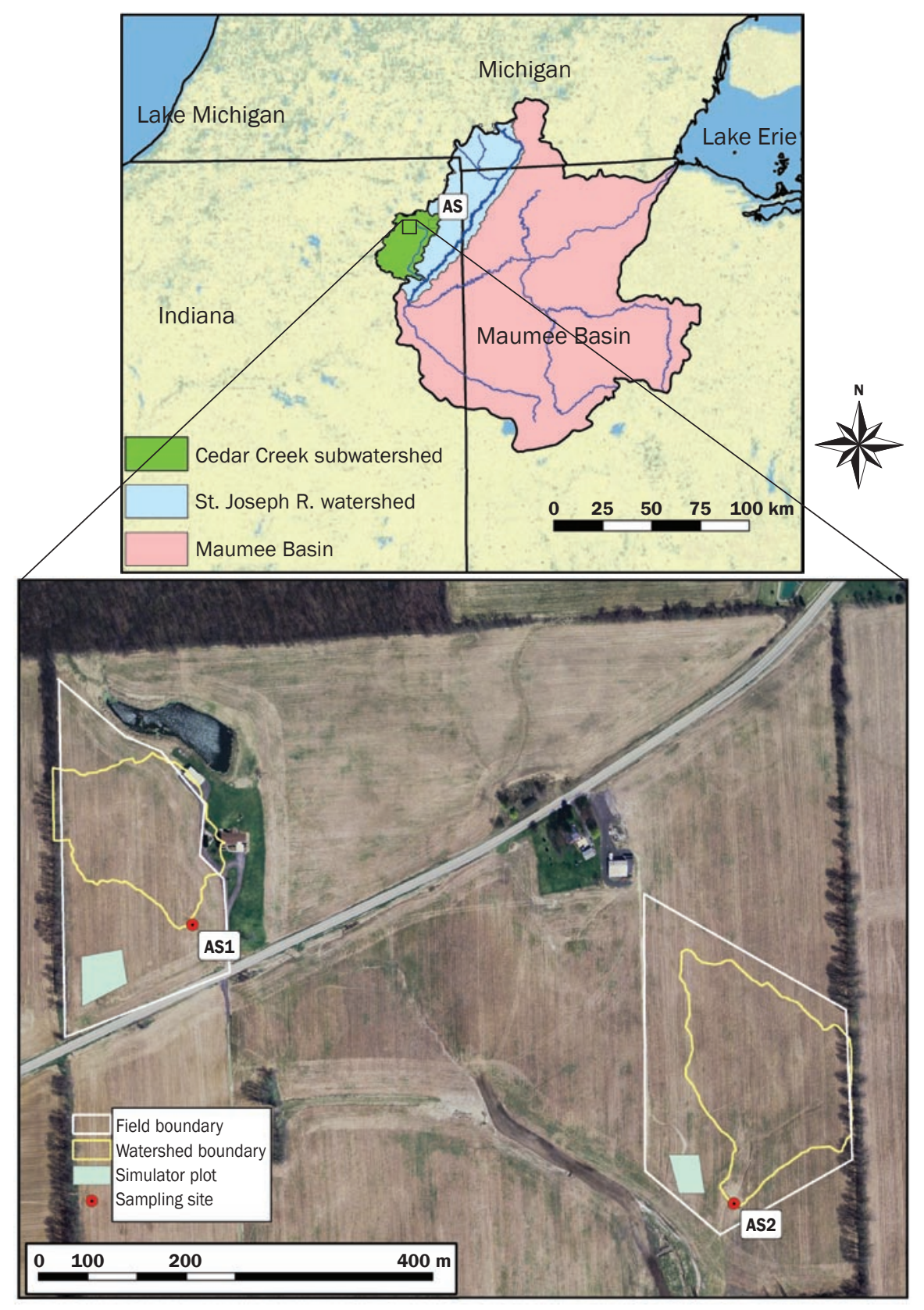

Precipitation rates were varied by adjusting the frequency of oscillations. Artificial rainfall was applied to plots for a total of $65 \mathrm{~min}$ utes, using a rate of $50 \mathrm{~mm} \mathrm{~h}^{-1}\left(2 \mathrm{in} \mathrm{hr}^{-1}\right)$ for the first 50 minutes and $75 \mathrm{~mm} \mathrm{~h}^{-1}$ (3 in $\mathrm{hr}^{-1}$ ) for the final 15-minute period. This represented a storm with a 50-year return period. Mean volumetric water content $(\theta \mathrm{v})$ values in plots prior to the start of rainfall simulations was $0.25 \mathrm{~cm}^{3} \mathrm{~cm}^{-3}\left(0.25 \mathrm{in}^{3} \mathrm{in}^{-3}\right)$ in 2004 and $0.32 \mathrm{~cm}^{3} \mathrm{~cm}^{-3}\left(0.32 \mathrm{in}^{3} \mathrm{in}^{-3}\right)$ in 2006. Runoff samples were collected every 5 minutes during the first 50 minutes of rainfall simulation, and every 3 minutes for the remaining 15-minute period. In most instances, there was not runoff at the 5- or 10-minute sample, which was recorded. A 60 $\mathrm{mL}(2 \mathrm{oz})$ sample was collected for analysis of total phosphorus (TP), and a $20 \mathrm{~mL}(0.7 \mathrm{oz})$ sample was collected for analysis of soluble phosphorus (SP). Specifics for analysis of SP and TP samples are presented below. For the rainfall simulations reported here, there were no applications of manure or fertilizer prior to simulated rainfall other than what was applied to the entire fields. Rainfall simulations on plots occurred between June 22 and June 25, 2004, and between June 7 and June 16, 2006. Corn plants were cut and removed from the plot area approximately 24 hours prior to rainfall simulations. Plots were covered if natural precipitation was forecast to avoid uncontrolled precipitation/runoff during the study period. Additional information about these plots can be found in Smith et al. (2007) or Warnemuende et al. (2007).

The AS1 and AS2 fields were located within $1 \mathrm{~km}$ (0.6 mi) of each other. Since 1990, both fields were cropped to corn (Zea mays L.) and soybean (Glycine $\max$ [L.] Merr.) in an annual rotation using continuous no-tillage. Corn was planted in both fields in 2004 and 2006 (table 1). In 2004, management in the AS1 field was unaltered (i.e., continuous no-tillage), while the management in the AS2 field changed from no-tillage to tillage prior to planting corn (i.e., rotational tillage). The soils in both fields were predominately Glynwood silt loam (Fine, illitic, mesic, Aquic Hapludalfs) and Blount silt loam (Fine, illitic, mesic, Aeric Epiagualfs). The soils were derived from glacial till, and slopes ranged from $2 \%$ to $10 \%$. Both fields, including the area outside of the monitored area, were approximately 6 ha $(15 \mathrm{ac})$ each. Each field contained small areas that drained to a single point (identified as watershed boundary in figure 2), where drop box weirs were installed, and wing walls were used to funnel excessive overland flow though the weirs. The monitored surface areas of the fields were 2.2 ha $(5.4 \mathrm{ac})$ for the AS1 field and 2.7 ha $(6.7 \mathrm{ac})$ for the AS2 field. During runoff events, discharge was measured in the drop box weirs using level transducers. During runoff events from the fields, a $300 \mathrm{~mL}(10$ oz) water sample was taken every 30 minutes using ISCO Avalanche autosamplers.

From the $300 \mathrm{~mL}(10 \mathrm{oz})$ water samples taken from each field, a $60 \mathrm{~mL}(2 \mathrm{oz})$ aliquot was taken for subsequent digestion and analysis of TP. Another $20 \mathrm{~mL}(0.7 \mathrm{oz})$ aliquot was filtered $(0.45 \mu \mathrm{m}$ [0.000018 in]) 
Table 1

Information about dates and inputs applied to the AS1 and AS2 fields.

\begin{tabular}{|c|c|c|}
\hline Date & AS1 & AS2 \\
\hline $5 / 2 / 2002$ & & Applied $40 \mathrm{~kg} \mathrm{ha}^{-1} \mathrm{~N}$ and applied $45 \mathrm{~kg} \mathrm{ha}^{-1} \mathrm{P}^{*}$ \\
\hline $5 / 6 / 2002$ & Applied $40 \mathrm{~kg} \mathrm{ha}^{-1} \mathrm{~N}$ and applied $45 \mathrm{~kg} \mathrm{ha}^{-1} \mathrm{P}$ & \\
\hline $5 / 24 / 2002$ & $\begin{array}{l}\text { Planted corn, applied } 149 \mathrm{~kg} \mathrm{ha}^{-1} \mathrm{~N} \text {, } \\
\text { and applied } 18 \mathrm{~kg} \mathrm{ha}^{-1} \mathrm{P}\end{array}$ & $\begin{array}{l}\text { Planted corn, applied } 149 \mathrm{~kg} \mathrm{ha}^{-1} \mathrm{~N} \text {, } \\
\text { and applied } 18 \mathrm{~kg} \mathrm{ha}^{-1} \mathrm{P}\end{array}$ \\
\hline $7 / 13 / 2002$ & Applied $91 \mathrm{~kg} \mathrm{ha}^{-1} \mathrm{~N}$ & \\
\hline $7 / 15 / 2002$ & & Applied $65 \mathrm{~kg} \mathrm{ha}^{-1} \mathrm{~N}$ \\
\hline $5 / 26 / 2003$ & Planted soybean & Planted soybean \\
\hline $4 / 12 / 2004$ & & Tilled \\
\hline $4 / 19 / 2004$ & Planted corn and applied $183 \mathrm{~kg} \mathrm{ha}^{-1} \mathrm{~N}$ & Planted corn and applied $183 \mathrm{~kg} \mathrm{ha}^{-1} \mathrm{~N}$ \\
\hline $5 / 18 / 2005$ & Planted soybean & Planted soybean \\
\hline $3 / 1 / 2006$ & & 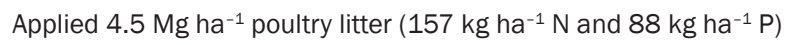 \\
\hline $3 / 6 / 2006$ & Applied $45 \mathrm{~kg} \mathrm{ha}^{-1} \mathrm{P}$ & \\
\hline $4 / 20 / 2006$ & & Tilled \\
\hline $4 / 22 / 2006$ & Planted corn and applied $161 \mathrm{~kg} \mathrm{ha}^{-1} \mathrm{~N}$ & Planted corn and applied $161 \mathrm{~kg} \mathrm{ha}^{-1} \mathrm{~N}$ \\
\hline
\end{tabular}

and acidified to $\mathrm{pH}<2$ with sulfuric acid. This aliquot was used for SP analysis. After initial processing and transport to the laboratory, all samples were frozen until SP and TP analyses were performed. All nutrient analyses were conducted colorimetrically with a Konelab Aqua 20 (EST Analytical, Medina, Ohio). Soluble P was analyzed on the filtered acidified samples using US Environmental Protection Agency method 365.2 (USEPA 1983). Total P was analyzed using US Environmental Protection Agency method 365.4 for TP (USEPA 1983) after sulfuric acid digestion of the unfiltered samples.

For plot-scale data, results from one rainfall simulation in both 2004 and 2006 were used. In the first analysis at the field scale, the data are represented as the flow-weighted concentration and cumulative load from all of the runoff events that occurred during the study periods. To calculate the flow-weighted concentration, the total mass of $\mathrm{P}$ was divided by the total discharge. In the second analysis, the mean observations for individual storms from the AS1 and AS2 fields in each year were compared to the mean observations of the plot-scale data. In this analysis, a means separation procedure was used for observations within a specific scale but not across the scales. For example, means separation was performed at the $2 \mathrm{~m}(6.6 \mathrm{ft})$ plot scale for plots in the AS1 and AS2 fields. This analysis was used to determine if the plot-scale data was yielding a similar trend compared to the field-scale data and if the separation of means observed at the field scale was also observed at the plot scales.

In addition to load and flow-weighted concentrations, a third metric, or similarity parameter, was calculated to assess $\mathrm{P}$ transport at the plot and field scales. This was accomplished by normalizing the P load for the amount of precipitation. We decided to normalize for the amount of precipitation because this is potentially a similarity parameter that could normalize contaminant losses based on the inputs into the system (amount of land contributing to the runoff and amount of precipitation driving the hydrology of the system). The precipitation for the rainfall simulations was calculated as the amount of precipitation applied using the simulators. The precipitation for the fields was calculated for the 2004 and 2006 study periods using tipping bucket rain gauges colocated with the monitoring equipment for each field.

Load and concentration data were log normally distributed and were therefore logtransformed prior to statistical analysis. The mean and the upper and lower confidence limits for plot-scale data were calculated using PROC MEANS in SAS (SAS Institute 1999). The cumulative observed values from both years (2004 and 2006) for field-scale data were then compared to the upper and lower confidence limits for the plot-scale data to determine if the plot-scale data gave a reasonable estimation of field-scale nutrient losses. A secondary statistical analysis was conducted to compare the mean values of individual runoff events from the fields to the plot-scale rainfall simulation data. This was accomplished by using the log-transformed data and making comparisons using analysis of variance (ANOVA) and Tukey's Least Significant Difference for comparison of means within a specified spatial scale in JMP v. 6.0.0 (SAS Institute 2005).

\section{Results and Discussion}

Runoff Coefficients. Runoff from plots was significantly greater than runoff from fields (table 2). When comparing plot runoff between the two fields for the same size plots, the values were not significantly different. Increasing plot length resulted in slight, but not significant, increases in runoff for both field in 2006 and in the AS2 field in 2004. Other studies have assessed runoff from various landscape positions and have found that while runoff can be produced from virtually any landscape position at the plot scale during runoff simulations, runoff water does not necessarily reach the field edge or stream (Buda et al. 2009).

Runoff coefficients were significantly greater from plots than from fields. Le Bissonnias et al. (1998) studied the effects of 


\section{Table 2}

Runoff (Q) and runoff coefficients (Q/P) from plots and fields in 2004 and 2006.

\begin{tabular}{|c|c|c|c|c|c|}
\hline \multirow[b]{2}{*}{ Field } & \multirow[b]{2}{*}{ Size } & \multicolumn{2}{|l|}{2004} & \multicolumn{2}{|l|}{2006} \\
\hline & & $\begin{array}{l}Q \\
(\mathbf{m m})\end{array}$ & $\begin{array}{l}\text { Q/P } \\
\text { (dimensionless) }\end{array}$ & $\begin{array}{l}Q \\
(\mathbf{m m})\end{array}$ & $\begin{array}{l}\text { Q/P } \\
\text { (dimensionless) }\end{array}$ \\
\hline AS1 & $2 \mathrm{~m}^{2}$ & $29.9 a *$ & $0.49 a$ & $10.3 b$ & $0.17 a b$ \\
\hline AS1 & $5 \mathrm{~m}^{2}$ & $28.7 a b$ & $0.47 a$ & $-\dagger$ & - \\
\hline AS1 & $10 \mathrm{~m}^{2}$ & $22.7 \mathrm{bc}$ & $0.38 a$ & $12.6 a b$ & $0.21 a$ \\
\hline AS1 & Field & $2.57 d$ & $0.09 b$ & $1.73 \mathrm{c}$ & $0.05 c$ \\
\hline AS2 & $2 \mathrm{~m}^{2}$ & $18.7 \mathrm{c}$ & $0.31 a$ & $12.2 \mathrm{ab}$ & $0.20 a$ \\
\hline AS2 & $5 \mathrm{~m}^{2}$ & 24.0abc & $0.40 a$ & - & - \\
\hline AS2 & $10 \mathrm{~m}^{2}$ & $23.8 a b c$ & $0.39 a$ & $14.1 a$ & $0.23 a$ \\
\hline AS2 & Field & $1.50 d$ & $0.08 b$ & $3.15 c$ & $0.10 b c$ \\
\hline
\end{tabular}

* Means within a column followed by the same letter are not significantly different.

† No $5 \mathrm{~m}^{2}$ plots were used in 2006 , thus there is no data available to present.

plot length on hydrology and sediment concentrations from several rainfall events. They found that as plot length increased from 1 to $62.5 \mathrm{~m} \mathrm{(3.3} \mathrm{to} 205 \mathrm{ft})$, the runoff coefficient initially increased from 1 to $10 \mathrm{~m}$ (3.3 to $33 \mathrm{ft})$. However, the largest slope length $(62.5 \mathrm{~m}[205 \mathrm{ft}])$ produced runoff coefficients $5 \%$ to $30 \%$ lower than those observed for the $1 \mathrm{~m}$ (3.3 ft) slope length. When the runoff coefficient was extrapolated to the watershed scale (approximately 150 ha [370 ac]), the runoff coefficient was consistently lower than the plots and ranged from about $5 \%$ to $55 \%$ of what was calculated for plots.

Assessment of "Spatial Directionality" for Annual Field Data. We compared the individual plot data from 2004 and 2006 to the cumulative field-scale P loss observations for those years. The mean and upper and lower confidence limits were calculated from the plot-scale data and were compared to the field observations (table 3). This approach allowed us to evaluate treatment or spatial "directionality" between the AS1 and AS2 fields, as well as temporal "directionality" due to the temporal variability in $\mathrm{P}$ loss from a given field for the two study years.

While P fertilizer history in the AS1 and AS2 fields was similar in 2004, there was greater SP loading from the no-tillage AS1 field than the tilled AS2 field (table 3). This would be an expected result because stratification of $\mathrm{P}$ in no-tillage fields has been a well-known problem that leads to greater $\mathrm{P}$ losses in runoff water, and disturbance of the soil has been one method recommended to minimize the impact of $\mathrm{P}$ stratification (Sharpley 2003). In 2006, there was a greater SP load from the AS2 field than the AS1 field, which one might assume to be a result of the greater rate of $\mathrm{P}$ fertilizer application to the AS2 field (tables 1 and 3). However, the flowweighted SP concentrations from the AS1 field were greater than from the AS2 field, and thus the difference in loading was a result of the $82 \%$ greater discharge from the AS2 field during 2006. As suggested by Kleinman et al. (2006), hydrology had a greater impact on P loading than soil chemistry.

Field-scale observations of SP and TP load did not fall within the confidence limits established by the plot-scale data in either 2004 or 2006 (table 3). However, the plot data was directionally correct in every instance, suggesting that the plot-scale data was able to detect the differences in $\mathrm{P}$ loading due to $\mathrm{P}$ stratification or $\mathrm{P}$ application from fertilizers. We can say that the 2004 data is directionally correct because the SP loads in 2004 were greater in all of the plots from the AS1 field than the AS2 field, and the observed SP load in 2004 was greater $\left(74.5 \mathrm{~g} \mathrm{ha}^{-1}\right.$ [0.066 $\left.\left.\mathrm{lb} \mathrm{ac}{ }^{-1}\right]\right)$ in the AS1 field than the AS2 field (10.7 $\left.\mathrm{g} \mathrm{ha}^{-1}\left[0.0095 \mathrm{lb} \mathrm{ac}^{-1}\right]\right)$. In 2004, TP loads from AS1 (406 $\mathrm{g} \mathrm{ha}^{-1}\left[0.36 \mathrm{lb} \mathrm{ac}^{-1}\right]$ ) were similar to those observed from AS2 (396 $\mathrm{g} \mathrm{ha}^{-1}\left[0.35 \mathrm{lb} \mathrm{ac}^{-1}\right]$ ), which were greater than the confidence limits established from plot data. However, there was overlap in the confidence limits for TP load established by the 2 and $5 \mathrm{~m}$ (6.6 and $16 \mathrm{ft})$ plots in these two fields. We propose that these overlaps in the confidence limits from the 2 and $5 \mathrm{~m}$ $(6.6$ and $16 \mathrm{ft})$ plots are another indication of directionality, since there was only a $2.5 \%$ difference in TP load values from the AS1 and AS2 fields.

The field-scale observations for precipitation normalized SP load were within the confidence limits of at least one set of the plot data for both fields in 2004 and 2006 (table 3). The precipitation normalized TP loads from both fields fell within the confidence limits established by plots in 2004 . However, the confidence limits established by plot data for TP were greater than the normalized TP load for the AS1 field in 2006, and the observed value for the AS2 field fell between the ranges in the 95\% confidence limits calculated from the 2 and $10 \mathrm{~m}$ (6.6 and $33 \mathrm{ft}$ ) plots in 2006.

The precipitation normalized SP loads from the entire growing season were seven times greater from the AS1 field than the AS2 field in 2004 (table 3). The plots in the AS1 field were 22 times greater $(2 \mathrm{~m}$ plots or 6.6 $\mathrm{ft}), 21$ times greater $(5 \mathrm{~m}$ plots [16 ft]), and 5 times greater $(10 \mathrm{~m}$ plots $[33 \mathrm{ft}])$ compared to the plots in the AS2 field. Since there was no overlap in the confidence limits for this metric in 2004, all the plot-scale data were directionally correct with respect to precipitation normalized SP loads. In 2006, both plot scales (2 and $10 \mathrm{~m}$ [6.6 and $33 \mathrm{ft}$ ]) were numerically greater from the AS2 field than the AS1 field; however, there was overlap in the confidence intervals from the plot-scale data. Both 2004 and 2006 data from the AS1 field seem to indicate that precipitation normalized SP loads from the larger plots $(10 \mathrm{~m}$ [33 ft]) appear to be the closest to resembling the loads observed from the field scale for the entire season. This assessment does not necessarily hold true for the AS2 field though. The only consistent management difference between these two fields is the tillage that occurred prior to planting corn both years. It is possible that when rainfall simulations are conducted in cropland, the flow-path length can have a strong impact on the resulting $\mathrm{P}$ losses. While this observation was not made for either loads or concentration for these sites, this discovery that the precipitation-normalized SP loads did follow this trend may indicate that there should be more work done using the normalized loads to determine if there is merit in its use for a real-world applications, such as a potential replacement for total maximum daily loads that accounts for hydrology and nonpoint source contributions to nutrient loading of streams.

The precipitation normalized TP loads in 2004 were $0.753 \mathrm{~g} \mathrm{ha}^{-1} \mathrm{~mm}^{-1}\left(0.0170 \mathrm{lb} \mathrm{ac}^{-1}\right.$ $\left.\mathrm{in}^{-1}\right)$ from the AS1 field and $0.735 \mathrm{~g} \mathrm{ha}^{-1} \mathrm{~mm}^{-1}$ $\left(0.0166 \mathrm{lb} \mathrm{ac}^{-1} \mathrm{in}^{-1}\right)$ from the AS2 field (table 3). Only the $2 \mathrm{~m}(6.6 \mathrm{ft})$ plots from these data appear to be directionally correct (i.e., similar 


\section{Table 3}

Evaluation of plot data from the AS1 and AS2 fields to compare "directionality."

\begin{tabular}{|c|c|c|c|c|c|c|c|c|c|c|c|c|c|}
\hline \multirow[b]{2}{*}{ Size } & \multirow[b]{2}{*}{ Variable } & \multicolumn{6}{|l|}{ AS1 field } & \multicolumn{6}{|l|}{ AS2 field } \\
\hline & & $\begin{array}{l}\text { SP load } \\
\left(\mathrm{g} \mathrm{ha}^{-1}\right)\end{array}$ & $\begin{array}{l}\text { TP load } \\
\left(\mathrm{g} \mathrm{ha}^{-1} \mathrm{~mm}^{-1}\right)\end{array}$ & $\begin{array}{l}\text { Normal } \\
\text { SP load } \\
\left(\mathrm{g} \mathrm{ha}^{-1} \mathrm{~mm}^{-1}\right)\end{array}$ & $\begin{array}{l}\text { Normal } \\
\text { TP load } \\
\left(\mathrm{g} \mathrm{ha}^{-1} \mathrm{~mm}^{-1}\right)\end{array}$ & $\begin{array}{l}\text { SP } \\
\text { concentration } \\
\left(\mathrm{mg} \mathrm{L}^{-1}\right)\end{array}$ & $\begin{array}{l}\text { TP } \\
\text { concentration } \\
\left(\mathrm{mg} \mathrm{L}^{-1}\right)\end{array}$ & $\begin{array}{l}\text { SP load } \\
\left(\mathrm{g} \mathrm{ha}^{-1}\right)\end{array}$ & $\begin{array}{l}\text { TP load } \\
\left(\mathrm{g} \mathrm{ha}^{-1}\right)\end{array}$ & $\begin{array}{l}\text { Normal } \\
\text { SP load } \\
\left(\mathrm{g} \mathrm{ha}^{-1} \mathrm{~mm}^{-1}\right)\end{array}$ & $\begin{array}{l}\text { Normal } \\
\text { TP load } \\
\left(\mathrm{g} \mathrm{ha}^{-1} \mathrm{~mm}^{-1}\right)\end{array}$ & $\begin{array}{l}\text { SP } \\
\text { concentration } \\
\left(\mathrm{mg} \mathrm{L}^{-1}\right)\end{array}$ & $\begin{array}{l}\mathrm{TP} \\
\text { concentration } \\
\left(\mathrm{mg} \mathrm{L}^{-1}\right)\end{array}$ \\
\hline \multicolumn{14}{|l|}{2004} \\
\hline \multirow[t]{3}{*}{$2 m$} & Mean & 22.7 & 151 & 0.452 & 2.99 & 0.121 & 0.794 & 0.940 & 131 & 0.0199 & 2.62 & 0.0077 & 0.931 \\
\hline & Upper CL & 48.2 & 307 & 0.879 & 5.28 & 0.276 & 1.54 & 1.52 & 232 & 0.0299 & 3.97 & 0.0105 & 1.39 \\
\hline & Lower CL & 10.6 & 74.1 & 0.233 & 1.70 & 0.0530 & 0.411 & 0.580 & 74.3 & 0.0132 & 1.73 & 0.0057 & 0.622 \\
\hline \multirow[t]{3}{*}{$5 \mathrm{~m}$} & Mean & 15.1 & 108 & 0.301 & 2.17 & 0.0757 & 0.538 & 0.360 & 38.0 & 0.0142 & 0.757 & 0.0061 & 0.216 \\
\hline & Upper CL & 29.8 & 177 & 0.570 & 2.97 & 0.154 & 0.751 & 8.63 & 233 & 0.118 & 4.45 & 0.0283 & 1.19 \\
\hline & Lower CL & 7.63 & 66.6 & 0.104 & 1.58 & 0.0371 & 0.385 & 0.015 & 6.20 & 0.0017 & 0.129 & 0.0013 & 0.0394 \\
\hline \multirow[t]{3}{*}{$10 m$} & Mean & 5.21 & 47.7 & 0.105 & 0.953 & 0.0428 & 0.378 & 0.926 & 206 & 0.0196 & 4.09 & 0.0064 & 1.17 \\
\hline & Upper CL & 13.0 & 109 & 0.243 & 1.90 & 0.114 & 0.631 & 1.70 & 363 & 0.0314 & 5.92 & 0.0101 & 1.60 \\
\hline & Lower CL & 2.08 & 20.9 & 0.046 & 0.478 & 0.0161 & 0.227 & 0.505 & 116 & 0.0122 & 2.82 & 0.0041 & 0.862 \\
\hline Field & Observed & 74.5 & 406 & 0.138 & 0.753 & 0.260 & 1.42 & 10.7 & 396 & 0.0197 & 0.735 & 0.0442 & 1.65 \\
\hline \multicolumn{14}{|l|}{2006} \\
\hline \multirow[t]{3}{*}{$2 m$} & Mean & 6.19 & 21.4 & 0.124 & 0.426 & 0.0805 & 0.275 & 9.74 & 61.8 & 0.195 & 1.23 & 0.106 & 0.665 \\
\hline & Upper CL & 8.61 & 33.5 & 0.164 & 0.602 & 0.102 & 0.388 & 15.7 & 71.5 & 0.299 & 1.52 & 0.141 & 0.697 \\
\hline & Lower CL & 4.45 & 13.7 & 0.094 & 0.302 & 0.0638 & 0.195 & 6.05 & 42.5 & 0.127 & 1.00 & 0.0790 & 0.633 \\
\hline \multirow[t]{3}{*}{$10 m$} & Mean & 1.48 & 5.33 & 0.031 & 0.106 & 0.0160 & 0.054 & 1.55 & 14.5 & 0.0325 & 0.289 & 0.0153 & 0.129 \\
\hline & Upper CL & 1.86 & 6.83 & 0.036 & 0.111 & 0.0190 & 0.056 & 4.82 & 25.5 & 0.0936 & 0.473 & 0.0437 & 0.216 \\
\hline & Lower CL & 1.19 & 4.15 & 0.026 & 0.101 & 0.0135 & 0.052 & 0.499 & 8.25 & 0.0113 & 0.177 & 0.0054 & 0.077 \\
\hline Field & Observed & 16.0 & 55.2 & 0.026 & 0.0882 & 0.152 & 0.521 & 54.6 & 307 & 0.0873 & 0.490 & 0.137 & 0.770 \\
\hline
\end{tabular}

Notes: $\mathrm{TP}=$ total phosphorus. $\mathrm{SP}=$ soluble phosphorus. $\mathrm{CL}=$ confidence limit.

but slightly greater normalized TP loads from AS1). In 2006, precipitation normalized TP loads were directionally correct at both the 2 and $10 \mathrm{~m}$ (6.6 and $33 \mathrm{ft})$ scales.

Flow-weighted SP concentrations were greater from the AS1 field than the AS2 field in both years (table 3). In 2004, the flow-weighted SP concentration from AS1 was nearly five times greater than what was observed from the AS2 field. In 2006, flowweighted SP concentrations were only $11 \%$ greater from the AS1 field than the AS2 field. There are two possible reasons why SP concentrations were slightly lower in the AS2 field compared to the AS1 during 2006, despite a greater rate of $\mathrm{P}$ application. The first reason is that the $\mathrm{P}$ applied to the AS2 field was incorporated via tillage, whereas there was only surface broadcast application of fertilizer in the AS1 field (Sharpley 2003). The second reason why there could potentially be lower P losses from the AS2 field is that the source of fertilizer was poultry litter, which tends to have lower solubility, and thus lower susceptibility to being lost via runoff than inorganic fertilizers (Smith and Moore 2005; Smith et al. 2007).

The observed flow-weighted SP concentration of $0.26 \mathrm{mg} \mathrm{L}^{-1}(0.26 \mathrm{ppm})$ from the AS1 field in 2004 and $0.137 \mathrm{mg} \mathrm{L}^{-1}$ from the AS2 field in 2006 did fall within the range of the confidence limits of the $2 \mathrm{~m}(6.6 \mathrm{ft})$ plots. The range established by the confidence limits was lower than the observed flow-weighted SP concentrations in 2004 from the AS2 field and in 2006 from the AS1 field.

Mean flow-weighted SP concentrations in 2004 were roughly an order of magnitude greater from plots constructed in the AS1 field compared to the AS2 field. These data would appear to be directionally correct, since the flow-weighted SP concentration at the field scale was almost six times greater from the AS1 field than the AS2 field. In 2006, field-scale flow-weighted SP concentrations were similar $(0.152$ and $0.137 \mathrm{mg}$ $\mathrm{L}^{-1}$, from AS1 and AS2, respectively). The plot-scale data would appear to be direction-

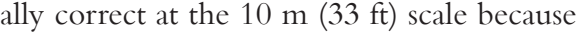
the values were similar, as indicated by the overlap in confidence limits, but numerically greater from the AS1 field. Similarly, flowweighted TP concentrations from the $2 \mathrm{~m}$ $(6.6 \mathrm{ft})$ plots in 2004 appear to be directionally correct with what was observed at the field scale. Flow-weighted TP concentrations were greater at both plot scales in 2006 from the AS2 field, as were the flow-weighted TP concentrations from the fields themselves.

AssessmentofInterannual "Directionality" for Annual Field Data. In terms of interannual "directionality," the plot data appear to be directionally correct in assessing which year (2004 or 2006) had greater SP or TP losses from the AS1 or AS2 fields. Data from the plots constructed in the AS1 field indicated that SP and TP loads, normalized SP and TP loads, and SP and TP concentrations should be greater in 2004 than 2006, which is confirmed by the observed $\mathrm{P}$ losses at the field scale for these two years. Other 


\section{Figure 3}

Comparisons between the AS1 and AS2 fields for the plot and field scales from 2004 for (a) soluble phosphorus (P) load, (b) precipitation normalized soluble P load, and (c) flow-weighted soluble $\mathrm{P}$ concentration.

(a)

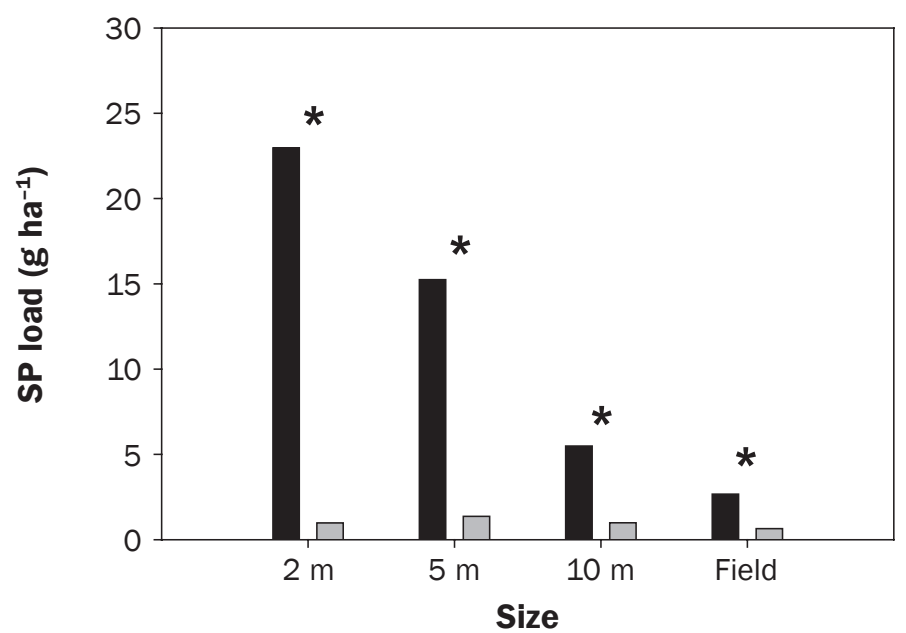

(b)

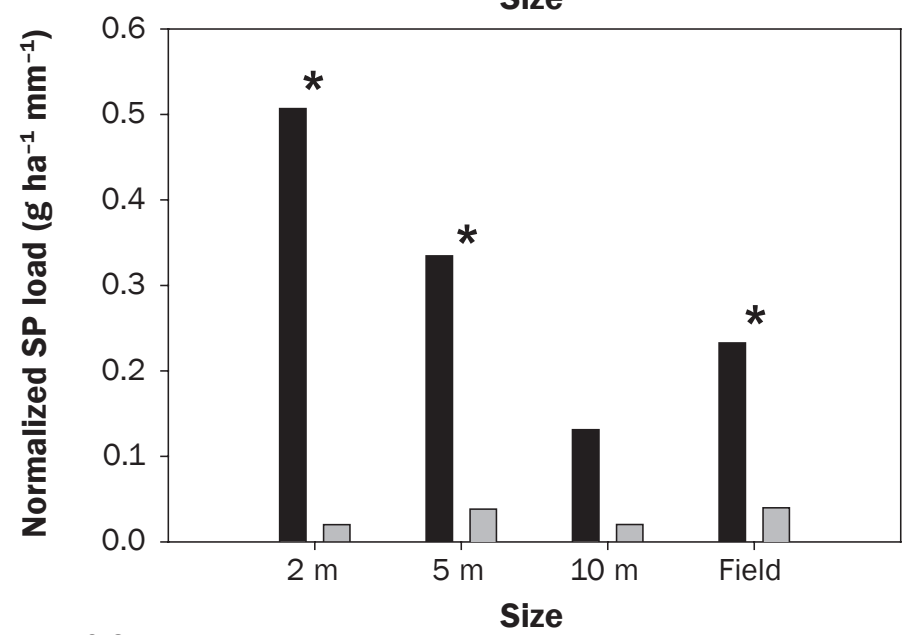

(c)

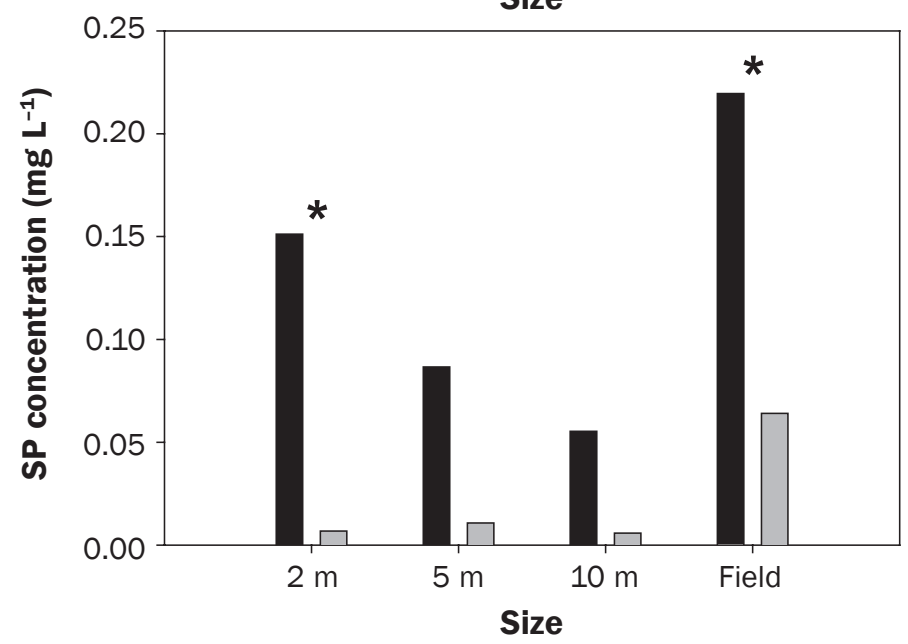

Legend

AS1

AS2

Note: $\mathrm{SP}=$ soluble phosphorus.

* Indicates a significant difference between treatments at the specified scale only. than tillage of the AS2 field, management for the two fields was identical for 2004 (table 1), whereas, in the spring of 2006 , approximately twice the amount of $\mathrm{P}$ was applied to the AS2 field compared to the AS1 field. The only other difference in the two study years was that 2006 was the second time tillage occurred in the AS2 field, which likely resulted in greater disruption of the macropores and bioturbation from longterm no-tillage compared to the tillage that occurred in 2004.

There was also a difference in precipitation and runoff response from the two fields. There was $87 \mathrm{~mm}$ (3.4 in) more precipitation in 2006 compared to 2004 (data not shown). There was similar runoff response from the two fields in 2004 (13 and 12 runoff events, and 28.6 and $24.1 \mathrm{~mm}$ [1.1 and 0.9 in] of runoff from the AS1 and AS2 fields, respectively). However, in 2006, there were 13 more runoff events, resulting in $29.2 \mathrm{~mm}$ (1.1 in) more runoff from the AS2 field than the AS1 field. For the AS2 field, SP losses were greater during 2006 than 2004, whereas TP losses were observed to be greater during 2004. When comparing data from the 2 and $10 \mathrm{~m}(6.6$ and $33 \mathrm{ft})$ plots constructed in this field during these two years, the data indicate the same interannual trends for SP and TP observed at the field scale occurred at both plot scales.

"Directionality" of Plot Data Compared to Means from Individual Storms. When comparing the plot-scale data to the mean observations from all storms that occurred at the AS1 and AS2 fields in 2004, all plot scales and the fields indicated significantly greater SP loads from the AS1 field than the AS2 field (figure 3a). Mean SP loads from the AS2 field were similar (0.65 to $1.37 \mathrm{~g} \mathrm{ha}^{-1}$ [0.00058 to $\left.\left.0.0012 \mathrm{lb} \mathrm{ac}^{-1}\right]\right)$, regardless of scale (i.e., no significant differences if all four scales are compared). However, the SP loads from the AS1 field decreased with increasing scale in 2004.

The precipitation normalized SP loads in 2004 were significantly greater from the AS1 field at the $2 \mathrm{~m}(6.6 \mathrm{ft}), 5 \mathrm{~m}$ (16 ft), and

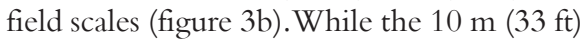
scale indicated greater normalized SP loads from the AS1 field, this was not significantly different. As with SP loads, the precipitation normalized SP loads were similar at all scales from the AS2 field (0.02 to $0.04 \mathrm{~g} \mathrm{ha}^{-1} \mathrm{~mm}^{-1}$ [0.0004 to $\left.\left.0.0009 \mathrm{lb} \mathrm{ac}^{-1} \mathrm{in}^{-1}\right]\right)$. 
Flow-weighted SP concentrations in 2004 were greater from the AS1 field at all scales, but this effect was only significant at the 2 $\mathrm{m}(6.6 \mathrm{ft})$ and field scales (figure 3c). When comparing these three variables (SP loads, normalized SP loads, and flow-weighted SP concentrations) from 2004, these results would appear to confirm directionality of data from the plot scale to the field scale. There were significant differences between data collected from the fields for all three variables at both the $2 \mathrm{~m}(6.6 \mathrm{ft})$ and the field scales. Thus, from this analysis of the 2004 data, we can conclude that the $2 \mathrm{~m}(6.6 \mathrm{ft})$ plots were better at evaluating the SP transport behavior at the field scale than the 5 or $10 \mathrm{~m}$ (16 or $33 \mathrm{ft}$ ) plots.

There were no significant differences between SP loads at any of the scales when comparing the two fields in 2006 (figure 4a). While there were slightly greater mean SP loads from the AS1 field (1.83 $\mathrm{g} \mathrm{ha}^{-1}[0.0016$ $\left.\mathrm{lb} \mathrm{ac}{ }^{-1}\right]$ ) than the AS2 field (1.41 $\mathrm{g} \mathrm{ha}^{-1}$ $\left.\left[0.0013 \mathrm{lb} \mathrm{ac}^{-1}\right]\right)$, this is opposite of the trend observed at the plot scale. However, since there is no significant difference at any scale, one could conclude that this data is directionally correct because the treatments are similar for mean SP loads.

Normalized SP loads in 2006 were numerically greater from the AS2 field than the AS1 field at all scales (figure 4b). While none of these comparisons were significant, at all scales the plot data did mimic what was observed at the field scale.

The only significant differences from 2006 for flow-weighted mean SP concentrations was from the fields (figure 4c), with the AS1 field $\left(0.22 \mathrm{mg} \mathrm{L}^{-1}\right)$ being greater than the AS2 field $\left(0.13 \mathrm{mg} \mathrm{L}^{-1}\right)$. If one were to assume which field would have greater flow-weighted SP concentrations from the plot-scale data, one would likely assume slightly greater SP concentration from the AS2 field or that the concentrations would be similar. Since this was not the case, the case for directionality may not apply to the means of flow-weighted concentrations from individual storms that occurred during 2006 at the field scale.

Few studies have been able to compare results at multiple scales, and fewer still have been able to compare results from plots to P losses from fields. DeLaune et al. (2004a; 2004b) developed a PI from plot scale (9.3 $\left.\mathrm{m}^{2}\left[100 \mathrm{ft}^{2}\right]\right)$ and applied the results to fields (0.405 ha $[1 \mathrm{ac}])$. They observed a strong

\section{Figure 4}

Comparisons between the AS1 and AS2 fields for the plot and field scales from 2006 for (a) soluble phosphorus (P) load, (b) precipitation normalized soluble P load, and (c) flow-weighted soluble $\mathrm{P}$ concentration.

(a)

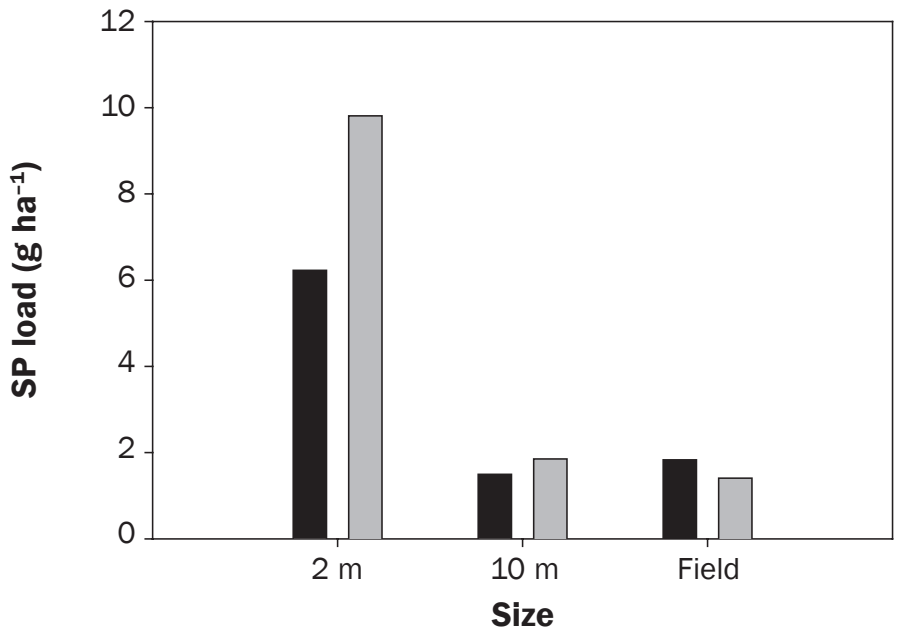

(b)

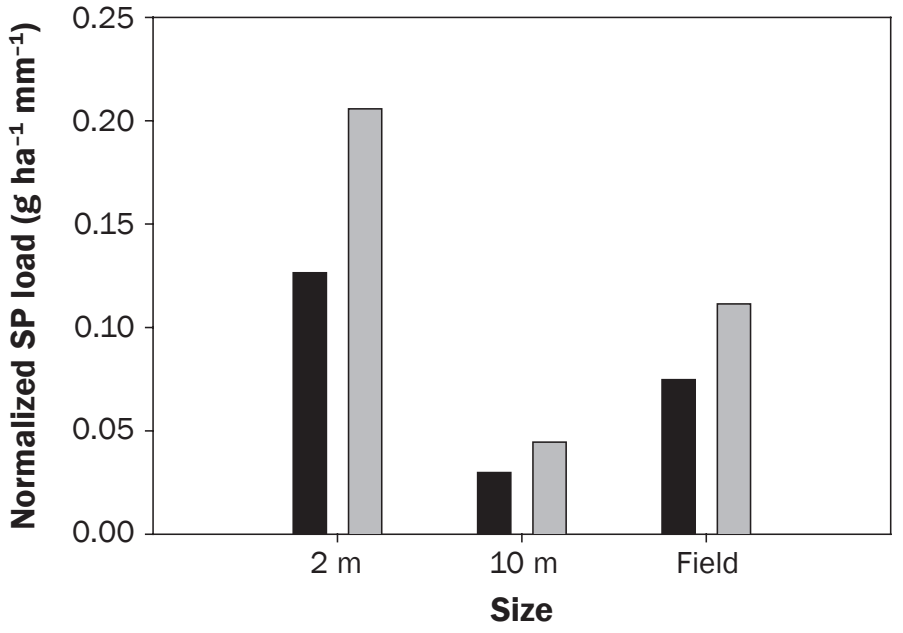

(c)

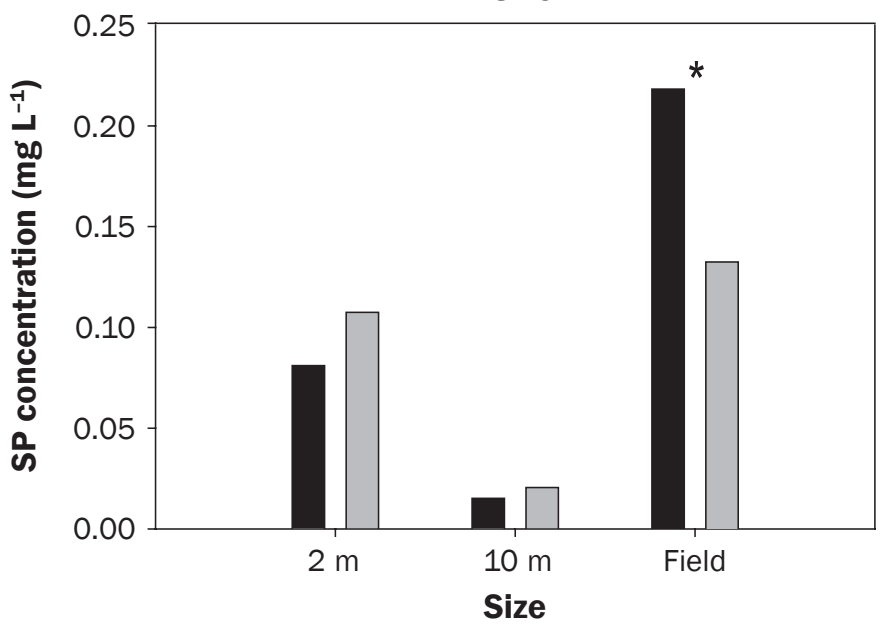

Legend $\square$ AS1 $\square$ AS2

Note: $\mathrm{SP}=$ soluble phosphorus.

* Indicates a significant difference between treatments at the specified scale only. 
correlation $\left(p<0.001, r^{2}=0.83\right)$ when the annual $\mathrm{P}$ loads from fields were regressed against PI ratings (DeLaune et al. 2004b). Another study compared $\mathrm{P}$ runoff from NPRP plots $\left(2 \mathrm{~m}^{2}\left[22 \mathrm{ft}^{2}\right]\right)$ to $\mathrm{P}$ runoff from a larger plot size $\left(32.6 \mathrm{~m}^{2}\right.$ [350 ft $\mathrm{ft}^{2}$ ) (Sharpley and Kleinman 2003). They observed comparable results between the two plot sizes; however, there were slightly lower SP concentrations from the larger plots when soils were similar. Another study compared P runoff from small boxes $\left(0.2 \mathrm{~m}^{2}\left[2 \mathrm{ft}^{2}\right]\right)$ and plots $\left(4 \mathrm{~m}^{2}\left[43 \mathrm{ft}^{2}\right]\right)$, and found a strong relationship in SP concentrations at these scales $(p<$ $\left.0.001, r^{2}=0.76\right)$ (Guidry et al. 2006).

\section{Summary and Conclusions}

We used two methods to compare plot-scale $\mathrm{P}$ transport to $\mathrm{P}$ losses from the fields. The first method was to compare the cumulative $\mathrm{P}$ losses from fields to confidence limits established by plot-scale rainfall simulations, and the second was to compare the means of $\mathrm{P}$ loss from individual storms at the field scale to the means of $\mathrm{P}$ loss from the plots. Both methods supported the hypothesis that plot-scale research should be used to support management decisions to improve runoff water quality at the field scale and thus supports the NPRP. A new metric was developed (precipitation normalized P loads). In this study, with these soils, this climate, and these managements, the precipitation normalized P loads from the plot scale were found to be similar to what was observed at the field scale, for both the cumulative $\mathrm{P}$ losses for a field during the year, as well as comparing $\mathrm{P}$ losses from individual storms that occurred at the field scale throughout the year.

\section{Acknowledgements}

The authors wish to thank the staff of the National Soil Erosion Research Laboratory in West Lafayette, Indiana, including Janae Bos, who is a biological science technician; Stan Livingston who is a soil scientist; Ben Zuercher who is a GIS database specialist; and the many students who helped with the sampling and analysis for this project. The authors would also like to thank Sara Walling, who is currently a water quality/nutrient management specialist with Wisconsin Department of Agriculture, Trade and Consumer Protection, Madison, Wisconsin, and Chris Smith, who is currently an engineering technician, with the USDA Natural Resources Conservation Service, Lebanon, Indiana. We would also like to thank the local landowners in the watershed for allowing us access to their land for these studies.

\section{References}

Bloschl, G., and M. Sivapalan. 1995. Scale issues in hydrological modeling: A review. Hydrological Processes 9(3-4):251-290.

Buda, A.R., P.J.A. Kleinman, M.S. Srinivasan, R.B. Bryant, and G.W. Feyereisen. 2009. Effects of hydrology and field management on phosphorus transport in surface runoff. Journal of Environmental Quality 38(6):2273-2284.

Carpenter, S.R., N.F. Caraco, D.L. Correll, R.W Howarth, A.N. Sharpley, and V.H. Smith. 1998. Nonpoint pollution of surface waters with phosphorus and nitrogen. Ecological Applications 8(3):559-568.

DeLaune, P.B., P.A. Moore, Jr., D.K. Carmen, A.N Sharpley, B.E. Haggard, and T.C. Daniel. 2004a Development of a phosphorus index for pastures fertilized with poultry litter - factors affecting phosphorus runoff. Journal of Environmental Quality 33(6):2183-2191.

DeLaune, P.B., P.A. Moore, Jr., D.K. Carmen, A.N Sharpley, B.E. Haggard, and T.C. Daniel. 2004b. Evaluation of the phosphorus source component in the phosphorus index for pastures. Journal of Environmental Quality 33(6):2192-2200.

Gachter, R., J.M. Ngatiah, and C. Stamm. 1998. Transport of phosphate from soil to surface waters by preferential flow. Environmental Science and Technology 32(13):1865-1869.

Guidry, A.R., F.V. Schindler, D.R. German, R.H. Gelderman, and J.R. Gerwing. 2006. Using simulated rainfall to evaluate field and indoor surface runoff phosphorus relationships. Journal of Environmental Quality 35(6):2236-2243.

Haygarth, P.M., L. Hepworth, and S.C. Jarvis. 1998. Forms of phosphorus transfer in hydrological pathways from soil under grazed grassland. European Journal of Soil Science 49(1):65-72.

Kleinman, P.J.A., A.N. Sharpley, T.L. Veith, R.O. Maguire, and P.A. Vadas. 2004. Evaluation of phosphorus transport in surface runoff from packed soil boxes. Journal of Environmental Quality 33(4):1413-1423.

Kleinman, P.J.A., M.S. Srinivasan, C.J. Dell, J.P. Schmidt, A.N. Sharpley, and R.B. Bryant. 2006. Role of rainfall intensity and hydrology in nutrient transport via surface runoff. Journal of Environmental Quality 35(4):1248-1259.

Le Bissonnais, Y.L., H. Benkhadra, V. Chaplot, D. Fox, D. King, and J. Daroussin. 1998. Crusting, runoff and sheet erosion on silty loamy soils at various scales and upscaling from $\mathrm{m}^{2}$ to small catchments. Soil and Tillage Research 46(1-2):69-80.

Pote, D.H., W.L. Kingery, G.E. Aiken, F.X. Han, P.A. Moore, Jr., and K. Buddington. 2003. Water-quality effects of incorporating poultry litter into perennial grassland soils. Journal of Environmental Quality 32(6):2392-2398.

SAS Institute. 1999. SAS User's Guide: Statistics. v. 8.0. Cary, NC: SAS Institute.
SAS Institute. 2005. JMP Statistical Discovery from SAS. Release 6.0.0. Cary, NC: SAS Institute.

SERA-17. 2008. National Research Project for Simulated Rainfall - Surface Runoff Studies. http://www.sera17. ext.vt.edu/Documents/National_P_protocol.pdf.

Sharpley, A.N. 2003. Soil mixing to decrease surface stratification of phosphorus in manured soils. Journal of Environmental Quality 32(4):1375-1384.

Sharpley, A., and P. Kleinman. 2003. Effect of rainfall simulator and plot scale on overland flow and phosphorus transport. Journal of Environmental Quality 32(6):2172-2179

Sivapalan, M., G. Bloschl, L. Zhang, and R. Vertessy. 2003. Downward approach to hydrological prediction. Hydrological Processes 17(11):2101-2111.

Smith, D.R., S.J. Livingston, B.W. Zuercher, M. Larose, G.C. Heathman, and C. Huang. 2008. Nutrient losses from row crop agriculture in Indiana. Journal of Soil and Water Conservation 63(6):396-409, doi:10.2489/jswc.63.6.396

Smith, D.R., and P.A. Moore, Jr. 2005. Soil extractable $\mathrm{P}$ changes with time after application of fertilizer 2: Manure from swine fed modified diets. Soil Science 170(7):640-651.

Smith, D.R., E.A. Warnemuende, C. Huang, and G.C. Heathman. 2007. How does the first year tilling longterm no-tillage field impact soluble nutrient losses in runoff? Soil and Tillage Research 95(1-2):11-18.

Sundareshwar, P.V., J.T. Morris, E.K. Koepfler, and B. Fornwalt. 2003. Phosphorus limitation of coastal ecosystem processes. Science 299(5606):563-565.

Suzuki, K., Y. Tanaka, K. Kuroda, D. Hanajima, and Y. Fukumoto. 2005. Recovery of phosphorus from swine wastewater through crystalization. Bioresource Technology 96(14):1544-1550.

USEPA (US Environmental Protection Agency). 1983 Methods for chemical analysis of water and wastes. EPA600/4-79-020. Cincinnati, OH: US Environmental Protection Agency.

Warnemuende, E.A., J.P. Patterson, D.R. Smith, and C. Huang. 2007. Effects of tilling no-till soil on losses of atrazine and glyphosate to runoff water under variable intensity simulated rainfall. Journal of Soil and Tillage Research 95(1-2):19-26 